\title{
Trend analysis of teenage pregnancy in Nigeria (1961-2013): how effective is the contraceptive use campaign
}

\author{
Adeniyi F. Fagbamigbe ${ }^{1}$, Rotimi F. Afolabi ${ }^{2}$, Oyindamola B. Yusuf ${ }^{3}$ \\ ${ }^{1}$ Division of Health Sciences, Populations, Evidence and Technologies Group, Warwick Medical School, \\ University of Warwick, Coventry, United Kingdom \\ ${ }^{1,2,3}$ Department of Epidemiology and Medical Statistics, Faculty of Public Health, College of Medicine, \\ University of Ibadan, Nigeria
}

\begin{abstract}
Article Info
Article history:

Received Nov 11, 2018

Revised Mar 19, 2019

Accepted Apr 12, 2019

\section{Keywords:}

Modern contraceptives

Nigeria

Public health

Teenage pregnancy

ABSTRACT

Teenage pregnancy (TP) is a recurrent global and public health problem. It poses both social and health challenges. Considering the massive campaign on the use of modern contraceptives to prevent TP in recent decades, we assessed trends in TP in Nigeria between 1961 and 2013. Pregnancy and contraception history of 70,811 women who were at least 20 years old when the Nigerian DHS was conducted in 1990, 2003, 2008, and 2013 respectively were used for the study, and descriptive statistics, time analysis techniques and multiple logistic regression were used to analyze the data at 5\% significance level. The overall prevalence of TP between 1961 and 2013 was $49.5 \%$ which fluctuated insignificantly during the studied period. The TP prevalence among women who entered adulthood in 1961 was $39.2 \%$, it peaked in 1978 at $58.9 \%$ before its unsteady decline to $39.6 \%$ in 2012 , and then rose sharply to $55.6 \%$ in 2013 . We predicted TP prevalence as $49.0 \%, 49.9 \%$ and $51.0 \%$ in 2014,2015 and 2016 respectively. The odds of TP were over 4 times higher in the North East and 5 times higher in the North West than in the South West. Teenagers with no education had higher odds of TP and it was higher among teenagers from the poorest households $(\mathrm{OR}=5.64,95 \% \mathrm{CI}=5.36-5.94)$. Rather than reducing with the worldwide acknowledged increase in contraceptive campaigns, TP increased over the years studied. As far as TP is concerned in Nigeria, the impact of the campaign on MC use is far from being effective. To achieve the objective of fewer TPs, fewer resources should be spent on access to contraception and instead diverted to areas more likely to achieve results such as improvements in educational achievement amongst girls.
\end{abstract}

Copyright $@ 2019$ Institute of Advanced Engineering and Science. All rights reserved.

\footnotetext{
Corresponding Author:

Adeniyi F. Fagbamigbe,

Department of Epidemiology and Medical Statistics,

Faculty of Public Health, College of Medicine,

University of Ibadan, Nigeria.

Email: franste174@yahoo.com
}

\section{INTRODUCTION}

Literature is replete with the fact that Teenage Pregnancy (TP) constitutes both health and social problems [1-3] and it is a public health challenge facing both developed and developing countries [4-5]. The challenges are irrespective of the teenager's marital status or legality of marriage [1], besides, pregnancy and childbirth-related complications are among the leading causes of mortality among persons aged 15-22 years in many parts of the world [6-9]. Teenage pregnancy is a major health challenge in every health care system because it could result in untoward effects on girls' physical, psychological, economic and social status [5]. That is why the health, social and developmental needs of young people are among the most 
important investments a country can make for both the individual girl's future and for the economic wellbeing of the country. Also, consequential effects of early pregnancy, early childbirth, and early marriage, limit the chances of attaining sound education and the likelihood of acquiring resourceful skills necessary to secure a good livelihood [9-11].

Several studies have identified many predictive factors of TP. Some of them include poor socio-economic background, peer pressure, early onset of menarche, poor education and poor reproductive health knowledge and practice [8,12-14]. A recent study in Peru found that the rate of early childbearing is nearly six times greater among teenagers from the poorest households compared to those from wealthiest households [15]. Peer pressure has been identified as another major cause of TP [16-17]. Teenagers often engage in unwholesome and unhealthy activities just to "belong"; hence, they are influenced by their peers to engage in an unsafe sexual activity. In support of this assertion, Rudd et al. stated that teenage girls undergo a lot of pressure to have sex, to look sexy and to conform to stereotypes of what the opposite sex sees as being attractive [18].

Also, rural-urban differentials have been reported to influence TP [19] with higher rates in rural areas $[4,12,15,20]$. Literature is at disagreement that sex education affects TP [3, 8]. Previous studies have established that many teenagers are not educated on methods of birth control [21], as sex education is a "no-go-area" in many cultures. Even where it exists, school-based sex education programmes only cater to in-school youths but not for out-of-school youths. Whereas, Mason-Jones et al found that sex education has little or no effect on TP [22]. Contraceptive use remains a big challenge among youths as inequalities, guardian consent, availability, and affordability, as well as poor bargaining power, are major barriers to contraceptive use in developing and developed nations alike [12].

TP rates vary across the globe. For instance, Romania recorded 61 TP per 1,000 teen-girls in 2011, the US had 72.2 per 1,000 in 2002-2005 [23] which later reduced to 57 per 1,000 in 2010, while England had 47 in 2011 [12]. In sub-Sahara Africa, birth rates were in the neighbourhood 150 per 1,000 women of ages 15 to 19 years [24] and Kenya had a TP rate of 174 per 1,000 teen girls aged 15-19 in 2012 [24]. In the US, $80 \%$ of TP are unintended, with about $58 \%$ resulting in live births, $14 \%$ in miscarriage and about $28 \%$ in abortion [25-26]. Early childbearing, the most prominent outcome of TP, has remained very prevalent in most regions of the world. In developing countries, adolescent girls aged 15-19 years had over 14 million births and 3 million abortions in 2008 alone [12]. About 16 million women aged 15-19 years give birth each year in the developing countries of which an estimated 3.9 million undergo unsafe abortions and are exposed to pregnancy complications including obstetric fistula, illness, injury, and death. These women account for $11 \%$ of all global annual births [27]. With $95 \%$ share of global births, the TP rates in middle income and low-income countries are twice and $500 \%$ of the rate in high-income nations respectively [27]. Specifically, $10 \%$ of girls become mothers by age 16 years in low- and middle-income countries, highest rates are found in sub-Saharan Africa with $12.2 \%$ in Mozambique [27].

A 2013 Population Reference Bureau (PRB) report shows that more than one-quarter of teen-girls aged 15 to 19 years from households in poorest wealth quintiles in Zimbabwe, Senegal, Colombia, and Peru have begun childbearing [15]. It is worth noting that half of all annual global births occur in just seven countries: Nigeria, Ethiopia, Democratic Republic of Congo, Bangladesh, Brazil and the United States of America [27]. This finding demonstrates the high rate of TP in both developing and developed countries $[6,28]$. However, a decline in the trend of TP has been documented. A report on TP prevention shows a historical decline between 1991 and 2005. This finding was attributed to a significant increase in the use of contraceptives among sexually active female teenagers[29]. Also, the number of births by teenagers in the US has generally declined, with some variations around 62\% between 1970 and 2014 [25]. Increased global attention to the prevention of TP worldwide is showing considerable positive results. These global trends in the decline of TP rates are viewed as a direct pointer to increasing opportunities and capacity of teenage girls to manage their sexual activities as well as their reproductive health [30]. This finding might be attributed to the significant increase recorded in contraceptive use and age at first marriage among adolescents, accompanied by a significant decrease in rates of adolescent childbearing in many countries and regions in recent years $[12,27]$. It is striking that while only a little difference exists in levels of sexual activity among adolescents in most nations, there is substantial variation in levels of contraceptive use and TP worldwide [12].

According to the 2006 Nigeria population census, $22 \%$ of the total population are teenagers [31] and Nigeria is one of the 21 countries recording highest rates of adolescent marriage before the 18th birthday [32]. The National Population Commission (NPC) of Nigeria estimated that occurrence of TP in Nigeria might have passed 60 million by 2015 compared with the recorded 44.5 million in 2006 [33]. Teenage Pregnancy has, therefore, remained a major health and social concern in Nigeria, coupled with its likely association with high child and maternal morbidity and mortality [34]. In 2008, the adolescent fertility rate in Nigeria was 121 live births per 1,000 [34], the highest rate in Africa, compared with 24.2 in 
the United States [25]. The large size of the incoming generation of youths is likely to cause an escalation in the absolute number of teenage births [35-36] as a result of likely high TP. Therefore, the TP rate is not only a social and health concern but also an undeniably powerful indicator of population dynamics and overall well-being of the Nigerian populace.

A major way to reduce TP is provision of a policy on the use of contraceptives. The Federal Government of Nigeria (FGN) is committed to achieving 36\% Contraceptive Prevalence Rate (CPR) by 2018 as a strategy for reducing unwanted pregnancy especially TP. As a matter of fact, Nigeria's annual vote for the procurement of reproductive health commodities in 2015 was $\$ 3$ million. The commodities include all materials needed by women to prevent unwanted pregnancy and practice safe sexual and reproductive health. There is a commitment to an additional annual boost of $\$ 8.35$ million over the next four years, an increase of almost $300 \%$. The FGN has agreed to work with the state and local governments to secure complementary budgets and also partner with other stakeholders to ensure family planning and reproductive health service delivery [37]. Similar commitments have been consistently made in recent past decades. Nonetheless, contraceptive use has its unintended consequences. While reducing TP, access to emergency contraception increases risky sexual activities which in turn increases [38-40].

However, the unanswered big question remains "to what extent has these budgetary allocations and mass contraceptive campaign impacted on TP in Nigeria?" Prevention of TP should be a priority for the public, policymakers, and nations because of its high economic, social, and health costs for teen-parents and their families [25]. However, without evidence and up-to-date review of what has been done and what was achieved, this goal may be difficult to achieve. The fact that TP is still prevalent globally [18, 24], especially in developing countries such as Nigeria with a huge contribution to the pool of the world TP, has necessitated the need to assess the trend in TP and the underlying factors. Therefore, in this study, we assessed the trends in TP from 1961 to 2013 and argued that the magnitude of TP is much larger than what is available in the literature. Most studies have estimated TP using numbers of "ever-had-a-birth female teenagers" or "currently pregnant female teenagers" in cross-sectional studies irrespective of the teen ages. In the current study, we used the date of the first occurrence of pregnancy among all women who have passed the teenage years to determine the rate of TP. We estimated and monitored the trend in TP and identified its risk factors.

\section{RESEARCH METHOD}

\subsection{Data sources}

In this study, data was utilized from four consecutive Nigerian Demographic Health Surveys conducted in 1990, 2003, 2008, and 2013 [34, 41]. The surveys were cross-sectional and nationally representative. They provided data about demographics and reproductive behavior of women of child-bearing age in Nigeria. In the 1990 survey, 299 sample clusters correspond to the Enumeration Areas (EA) of the National Integrated Survey of Households (NISH) master sample. A sample of 10,000 households was designed with twofold oversampling of the urban stratum, yielding 132 urban EAs and 167 rural EAs. In the 2003 survey, the 1991 census was used to select the sample using a stratified, two-stage cluster design. A total of 365 clusters were selected, 165 in urban and 200 in rural areas. Four-stage sampling procedures were adopted in the 2008 and 2013 surveys. The stages were a selection of local government areas on the rural-urban basis from every state and the Federal Capital Territory (FCT), selection of clusters and households, and finally the selection of individuals. Well-trained interviewers administered the pre-tested, semi-structured questionnaire on the individual women during face-to-face interviews.

\subsection{Data}

A total of 8,781, 7,620, 33,385 and 38,948 women participated in the surveys held in 1990, 2003, 2008, and 2013 respectively. The effective sample size included in this study was 70,811 consisting of 7,103, $5,871,26,794$ and 31,043 women who had attained age 20 years as at the respective date of the surveys. The outcome of interest in this study was TP. We defined TP to be conception by a woman before attaining age 20 years [10, 42] irrespective of whether the pregnancy resulted in childbirth or was terminated voluntarily or not. We, therefore, considered responses of women who had already completed the teen years. Three variables: "Age of respondent at $1^{\text {st }}$ birth", "Have you ever had a pregnancy that miscarried, was aborted, or ended in a stillbirth?" and "When did the last such pregnancy end?" in the dataset were used in determining women who were pregnant before age 20 years. The variables were used to determine those who reported pregnancy before age 20 years, those who had any childbirth before attaining age 20 years, and those who had used anything to terminate a pregnancy before they (women) attained age 20 years. The outcome variable was dummy coded (Yes/No) with the aim of interpreting all associative findings as 'having had TP'. However, dominant responses came from teenagers who were at nodal ages such as 15 and 
20; some teenagers who reported exact age 20 years to any of the three variables might have been pregnant before or shortly after age 20 years. We envisaged that this would have minimal effect on our findings. Therefore, for the purpose of this study, teenagers are young women between the ages of 13 and 20 years.

On the significance of the variables associated with TP in public health literature, the explanatory variables included in the current study are the basic socio-demographic variables such as residence (urban/rural); region of residence (North Central, North East, North West, South East, South South \& South West), wealth quintiles (Poorest, Poorer, Middle, Richer and Richest) and education (No formal education, Primary/Quranic, secondary and higher level). Others are cultural factors such as ethnicity (Hausa/Fulani, Yoruba, Igbo, and Others) and religion (Catholics, Other Christian, Islam and Others), fertility indicators such as marital status (married before age 20 years or later) and age at first marriage ( $<15$ years, 15 to 19 years $\&>19$ years) and awareness of contraceptives (Yes/No), current use of contraceptives (Yes/No), and years since adulthood calculated as number of years between when the respondents turned 20 and 2013 (the date of the last survey).

\subsection{Data analysis}

We used descriptive statistics and time analysis techniques, including trend lines and moving averages, to illustrate variations and trends in TP. The time series analysis involved computation of autocorrelation and partial autocorrelation using ARIMA models. Given a series of observations $y_{i}$ at different time points $i$, autocorrelation is a measure of linear dependence of a variable with itself at two different points in time. The autocorrelation between two consecutive observations depends basically on the time lag $\mathrm{h}$ between them in a stationary process. If $\mathrm{y}_{\mathrm{h}}=\operatorname{Cov}\left(\mathrm{y}_{\mathrm{t}}, \mathrm{y}_{\mathrm{t}-\mathrm{h}}\right)$ then the autocorrelation for lag- $h$ is given by:

$$
\mathrm{p}_{\mathrm{h}}=\operatorname{Corr}\left(\mathrm{y}_{\mathrm{t}}, \mathrm{y}_{\mathrm{t}-\mathrm{h}}\right)=\frac{\mathrm{y}_{\mathrm{h}}}{\mathrm{y}_{0}},
$$

where $\mathrm{y}_{0}$ is the unconditional variance attributed to the process. The partial autocorrelation, $\phi_{\mathrm{h}, \mathrm{h}_{\mathrm{h} . \mathrm{h}}}$ is the autocorrelation between $\mathrm{y}_{\mathrm{t}}$ and $\mathrm{y}_{\mathrm{t}-\mathrm{h}}$ after removing any linear dependence on $\mathrm{y}_{1}, \mathrm{y}_{2}, \ldots \ldots . \mathrm{y}_{\mathrm{t}-\mathrm{h}+1}$.

We fitted both linear and polynomial regression models to the yearly rates of TP and predicted TP prevalence in Nigeria for years 2014, 2015 and 2016. Chi-square tests and binary logistic regression models were used to investigate the association between the explanatory and outcome variables. For ease of analysis, we categorized the women into 5-year cohorts, starting from 1961, according to the years they exited teen ages. All analyses were conducted using Stata version 13 at 5\% significance level and data were weighed and adjusted for survey design and sampling errors.

\section{RESULTS AND DISCUSSIONS}

\subsection{Result}

Among the 70,811 women involved in the analysis, $65.3 \%$ were rural dwellers, $44.1 \%$ had no formal education and $20.5 \%$ had primary or Quranic education, while $26.4 \%$ had secondary school or higher education. Also, $62.2 \%$ had married as teenagers while $24.0 \%$ were married before age 15 years, it is presented in Table 1. In all, 56.4\% of rural teenagers compared to $36.9 \%$ of their urban counterparts were pregnant before attaining age 20 years. TP reduced gradually among urban women from $43.4 \%$ in 1990 to $35.0 \%$ in 2013. Over the same period, TP increased from $56.7 \%$ to $58.8 \%$ among rural women. While TP fell among women belonging to households in the richest quintiles from $41.6 \%$ to $23.2 \%$ between 1990 and 2013, it increased from $58.4 \%$ to $71.2 \%$ among those in poorest households' category. Other noticeable wide gaps existed in marital status, age at first marriage, religion, ethnicity and geographical zone of residence. All the factors considered were significantly associated with TP both in the overall and at each year of surveys.

The yearly prevalence of TP in Nigeria by 5 -year cohorts is shown in Table 2 . It seemed to be lower among women that exited the teen ages between 1961 and 1964 and then rose to about $58 \%$ among those that exited the teen ages during the 1974-1978 period, before declining over the years to $48 \%$ among those that exited the teen ages in 2009-2013. The overall prevalence of TP between 1961 and 2013 was $49.6 \%$. The time plot of TP prevalence by years when the respondents exited teen years is shown in Figure 1. It shows that the prevalence of TP among the studied women who have passed the teen ages fluctuated during the period. While the TP hovered around 50\% between 1961 and 1970, it went up as high as 60\% in certain years between 1975 and 1985 and reduced gradually thereafter though it seemed to be increasing by 2013. We explored the time analysis of the yearly prevalence of TP in Nigeria using a 2-period moving average method. The method showed a clearer peak in the trend. Generally, TP began to rise in 1962, 
started declining from 1967 to 1972 , rose to the highest rate of $58.9 \%$ in 1979 , then reduced gradually till 1995 and thereafter had a seemingly stable rate till 2013. It, however, peaked in 1979 is shown in Figure 1.

Table 1. Distribution of respondents and prevalence of teenage pregnancy by socio-demographic factors

\begin{tabular}{|c|c|c|c|c|c|c|}
\hline \multirow[b]{2}{*}{ Variables } & \multirow{2}{*}{$\begin{array}{c}\text { Distribution } \\
\text { of } \\
\text { respondents }\end{array}$} & \multicolumn{5}{|c|}{ Proportion (\%) ever pregnant before age 20 years } \\
\hline & & $\begin{array}{c}1990 \\
\mathrm{n}=7103\end{array}$ & $\begin{array}{c}2003 \\
n=5871\end{array}$ & $\begin{array}{c}2008 \\
n=26794\end{array}$ & $\begin{array}{c}2013 \\
n=31043\end{array}$ & $\begin{array}{c}\text { All } \\
\mathrm{n}=70811\end{array}$ \\
\hline \multicolumn{7}{|l|}{ Residence } \\
\hline Urban & 34.7 & 43.4 & 42.3 & 35.5 & 35.0 & 36.9 \\
\hline Rural & 65.3 & 56.7 & 57.1 & 55.0 & 58.8 & 56.4 \\
\hline \multicolumn{7}{|l|}{ Zone } \\
\hline North Central & 17.3 & 54.5 & 49.2 & 46.5 & 40.9 & 46.0 \\
\hline North East & 17.3 & 61.0 & 68.5 & 65.3 & 63.7 & 64.8 \\
\hline North West & 25.0 & 61.7 & 70.1 & 67.4 & 70.2 & 67.6 \\
\hline South East & 11.2 & 45.6 & 29.0 & 27.7 & 26.6 & 29.5 \\
\hline South South & 13.5 & 52.3 & 44.6 & 40.4 & 41.8 & 42.0 \\
\hline South West & 15.8 & 35.1 & 26.3 & 28.1 & 28.8 & 29.3 \\
\hline \multicolumn{7}{|l|}{ Education } \\
\hline None & 44.1 & 59.2 & 69.4 & 67.3 & 69.5 & 66.7 \\
\hline Primary/Quranic & 20.5 & 53.8 & 56.2 & 55.4 & 57.7 & 55.9 \\
\hline Secondary & 26.4 & 26.3 & 28.0 & 28.3 & 31.6 & 29.3 \\
\hline Higher & 9.1 & 10.0 & 15.8 & 11.0 & 11.7 & 11.5 \\
\hline \multicolumn{7}{|l|}{ Wealth Status } \\
\hline Poorest & 20.7 & 58.4 & 64.5 & 64.3 & 71.2 & 65.5 \\
\hline Poorer & 20.1 & 58.0 & 61.1 & 62.0 & 63.2 & 61.8 \\
\hline Middle & 19.0 & 55.2 & 57.5 & 52.0 & 52.8 & 52.9 \\
\hline Richer & 19.8 & 50.4 & 49.2 & 39.7 & 41.0 & 42.0 \\
\hline Richest & 20.5 & 41.6 & 28.5 & 22.9 & 23.2 & 26.1 \\
\hline \multicolumn{7}{|l|}{ Tribe } \\
\hline Hausa/Fulani & 29.9 & na & 74.0 & 69.5 & 70.7 & 70.2 \\
\hline Yoruba & 14.4 & & 27.8 & 27.7 & 26.5 & 27.0 \\
\hline Igbo & 13.9 & & 29.6 & 26.1 & 25.9 & 26.4 \\
\hline Others & 41.8 & & 56.2 & 49.5 & 48.2 & 49.7 \\
\hline \multicolumn{7}{|l|}{ Religion } \\
\hline Catholics & 12.6 & 43.9 & 38.5 & 36.2 & 31.7 & 37.3 \\
\hline Other Christian & 34.9 & 44.6 & 38.5 & 35.2 & 35.6 & 35.8 \\
\hline Islam & 46.5 & 57.8 & 34.3 & 63.1 & 63.7 & 61.7 \\
\hline Others & 6.0 & 52.7 & 65.1 & 57.5 & 55.2 & 61.9 \\
\hline \multicolumn{7}{|l|}{ Marriage Time } \\
\hline Before Age 2- Years & 62.2 & 75.3 & 70.1 & 77.1 & 75.3 & 77.2 \\
\hline Age 20 or After & 37.8 & 7.4 & 5.9 & 6.8 & 7.8 & 7.4 \\
\hline \multicolumn{7}{|l|}{ Age at $1^{\text {st }}$ Marriage } \\
\hline B4 15 & 24.0 & 84.6 & 74.6 & 87.1 & 84.2 & 89.8 \\
\hline $15-19$ & 38.2 & 69.5 & 66.7 & 69.0 & 70.0 & 70.0 \\
\hline Unmarried b4 20 & 37.8 & 7.4 & 5.9 & 6.8 & 7.8 & 7.4 \\
\hline Total & 100.0 & 51.6 & 51.4 & 48.9 & 49.5 & 49.6 \\
\hline
\end{tabular}

Table 2. Prevalence of teenage pregnancy by years of survey and 5-year cohorts in Nigeria: 1961-2013

\begin{tabular}{cccccc}
\hline 5 Year & \multicolumn{5}{c}{ Prevalence by Years of Survey } \\
Cohort & 1990 & 2003 & 2008 & 2013 & Overall \\
\hline $1961-1964$ & 42.1 & & & & 42.1 \\
$1966-1970$ & 46.4 & & & & 46.4 \\
$1971-1975$ & 47.8 & & & & 47.8 \\
$1974-1978$ & 57.1 & 58.0 & & & 57.4 \\
$1979-1985$ & 55.7 & 57.1 & 53.5 & & 54.7 \\
$1986-1990$ & 53.3 & 58.6 & 52.0 & 54.1 & 53.6 \\
$1991-1994$ & & 54.8 & 48.9 & 49.7 & 49.9 \\
$1995-1998$ & & 47.0 & 49.5 & 49.6 & 49.2 \\
$1999-2003$ & & 44.3 & 47.7 & 49.2 & 47.9 \\
$2004-2008$ & & & 45.9 & 48.6 & 47.3 \\
$2009-2013$ & & & & 47.9 & 47.9 \\
Total & 51.6 & 51.4 & 48.9 & 49.5 & 49.6 \\
\hline
\end{tabular}

We estimated autocorrelations (AC) and partial correlation from lag 1 to lag 8 representing the last eight years of the study period. The AC between 2013 and 2012 series was 0.283 , while it was 0.433 between 2013 and 2011. Actually, we expected these autocorrelations to gradually decrease to zero, but due to nonlinearity existing in the data, we observed an abnormal pattern. In essence, the AC results showed that TP 
is not a random process, but follows a particular distribution or model which is likely to be nonlinear (not shown in the tables).

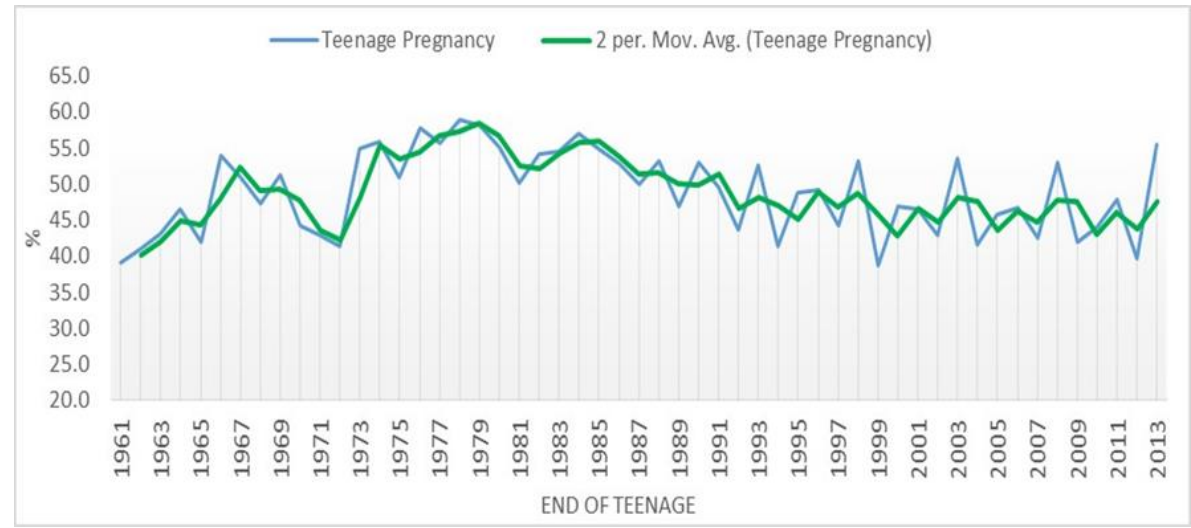

Figure 1. Time analysis of TP in Nigeria, 1961-2013

\section{Estimating and predicting the pattern of TP in Nigeria}

We explored two models to determine the pattern and estimate the trend of TP in Nigeria. The resultant linear model shows that TP fell gradually in Nigeria between 1961 and 2013. However, the polynomial model shows that the trend of TP in Nigeria was not linear but cyclical. The polynomial curve also shows some periodical fluctuations in the prevalence of TP in Nigeria. A sharp increase between 1973 and 1983 and decline from 1985 to 2005 are obvious. The polynomial model $\left(\mathrm{R}^{2}=0.4232\right)$ was found to have accounted for more variability in the data than the linear model $\left(\mathrm{R}^{2}=0.0167\right)$ as shown in Figure 2. Going by the polynomial model, we predicted that prevalence of TP would be $49.0 \%$, $49.9 \%$ and $51.0 \%$ among women transiting from the teen ages to adulthood in the years 2014, 2015 and 2016 respectively.

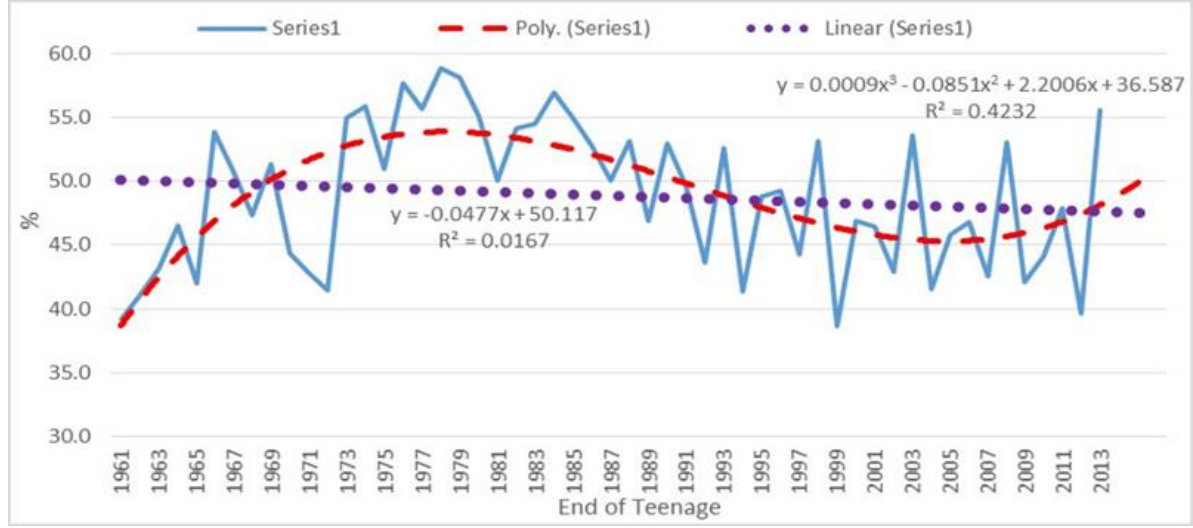

Figure 2. Modelling prevalence of teenage pregnancy 1961-2013

We monitored the exact ages at which the women had first pregnancy and computed the separate probabilities of first pregnancy at the exact ages among ever-pregnant women and also among all women. The exact age with the highest probability of first pregnancy was 15 years in the 1990 and 2003 surveys, 17 years in 2008 and 2013, and 17 years on the average across the survey years. Also, 58\% of the ever-pregnant women had their first pregnancy before age 20 years compared to $49.5 \%$ recorded among all women as shown in Table 3.

The unadjusted logistic regression carried out to determine the risk factors of TP in Nigeria showed that odds of TP increased by $0.6 \%$ for every additional year since a woman exited teen years between 1961 and 2013. Our analysis also revealed that the odds of TP were 17\% and $11 \%$ higher in 1990 and 2003 
respectively than in 2013. The odds of TP were over 4 times higher in the North East and 5 times higher in the North West than in the South-West. As expected, odds of TP was about 38 times $(\mathrm{aOR}=38.295 \% \mathrm{CI}=36.3-40.1)$ among women that got married before age 20 years. Educational attainment of the teenagers was also significant with higher odds among those without any formal education as shown in Table 4. However, the adjusted odds ratios from the multiple logistic regression revealed that the years since adulthood (since exiting teen ages) did not significantly predict TP while controlling for other factors. Education, region of residence, religion, ethnicity and age at first marriage significantly predicted $\mathrm{TP}$ in Nigeria.

Table 3. Distribution of probabilities of age at first pregnancy by survey year, ever pregnant and all women: 1961-2013

\begin{tabular}{|c|c|c|c|c|c|c|c|c|c|c|c|c|c|c|c|c|c|c|c|c|}
\hline \multirow[b]{2}{*}{ Age } & \multicolumn{5}{|c|}{ Among ever pregnant women } & \multicolumn{5}{|c|}{ Cumulative among pregnant } & \multicolumn{5}{|c|}{ Among all women } & \multicolumn{5}{|c|}{ Cumulative among all women } \\
\hline & All & $1990^{\circ}$ & 2003 & 2008 & 2013 & All & 1990 & 2003 & 2008 & 2013 & All & 1990 & 2003 & 2008 & 2013 & All & 1990 & 2003 & 2008 & 2013 \\
\hline 11 & 0.2 & 1.0 & 0.1 & 0.1 & 0.0 & 0.3 & 1.8 & 0.1 & 0.2 & 0.0 & 0.2 & 0.8 & 0.1 & 0. & 0.0 & 0.3 & 1.5 & 0.1 & 0.2 & 0.0 \\
\hline 12 & 1.7 & 2.1 & 1.8 & 1.8 & 1.2 & 2.0 & 3.9 & 1.9 & 2.0 & 1.3 & 1.4 & 1.8 & 1.5 & 1.5 & 1.1 & 1.7 & 3.4 & 1.6 & 1.7 & 1.1 \\
\hline 14 & 5.3 & 5.0 & 7.0 & 5.2 & 5.1 & 9.9 & 12.4 & 12.5 & 9.7 & 8.6 & 4.5 & 4.3 & 5.9 & 4.4 & 4.4 & 8.5 & 10.6 & 10.4 & 8.3 & 7.3 \\
\hline 15 & 9.1 & 10.0 & 10.4 & 8.9 & 8.7 & 19.0 & 22.4 & 22.9 & 18.6 & 17.3 & 7.7 & 8.6 & 8.6 & 7. & 7.4 & 16.2 & 19.3 & 19.1 & 15.9 & 14.8 \\
\hline 16 & 9.5 & 8.8 & 10.0 & 9.4 & 9.9 & 28.5 & 31.2 & 32.9 & 28.0 & 27.1 & 8.1 & 7.6 & 8.3 & 8.0 & 8.5 & 24.3 & 26.8 & 27.4 & 23.9 & 23.2 \\
\hline 17 & 10.4 & 10.3 & 9.8 & 10.2 & 10.8 & 38.9 & 41.6 & 42.6 & 38.2 & 37.9 & 8.8 & 8.9 & 8.2 & 8.7 & 9.2 & 33.2 & 35.7 & 35.6 & 32.6 & 32.5 \\
\hline Never & & & & & & & & & & & 14.6 & 14.0 & 16.6 & 14.7 & 14.3 & 100 & 100 & 100 & 100 & 100 \\
\hline
\end{tabular}

Table 4. Unadjusted and adjusted odds of predicting TP among women in Nigeria: 1961-2013

\begin{tabular}{|c|c|c|c|c|}
\hline Variable & OR $(95 \%-\mathrm{CI})$ & $\rho$-value & OR $(95 \%-\mathrm{CI})$ & $\rho$-value \\
\hline Years since adulthood & $1.006(1.004-1.008)$ & 0.000 & $0.981(0.978-1.000)$ & 0.235 \\
\hline \multicolumn{5}{|l|}{ Year of Survey } \\
\hline 1990 & $1.07(1.01-1.12)$ & 0.014 & \multirow[t]{5}{*}{$\mathrm{a}$} & \\
\hline 2003 & $1.11(1.05-1.17)$ & $<0.001$ & & \\
\hline 2008 & $1.01(0.98-1.04)$ & 0.525 & & \\
\hline 2013 & & & & \\
\hline \multicolumn{4}{|l|}{ Zone } & \\
\hline North Central & $1 . .98(1.88-2.09)$ & $<0.001$ & $0.94(0.84-1.05)$ & 0.282 \\
\hline North East & $4.34(4.11-4.59)$ & $<0.001$ & $1.14(1.01-1.29)$ & 0.026 \\
\hline North West & $5.23(4.97-5.51)$ & $<0.001$ & $0.90(0.89-1.18)$ & 0.113 \\
\hline South East & $1.02(0.96-1.08)$ & 0.567 & $1.19(1.01-1.44)$ & 0.042 \\
\hline South South & $1.76(1.66-1.86)$ & $<0.001$ & $1.55(1.37-1.71)$ & $<0.001$ \\
\hline \multicolumn{5}{|l|}{ South West } \\
\hline \multicolumn{5}{|l|}{ Education } \\
\hline None & $4.82(4.63-5.01)$ & $<0.001$ & 1.55 (1.44-1.67) & $<0.001$ \\
\hline Primary/Quranic & $3.02(2.89-3.16)$ & $<0.001$ & $1.60(1.50-1.71)$ & $<0.001$ \\
\hline \multicolumn{5}{|l|}{ Secondary+ } \\
\hline \multicolumn{5}{|l|}{ Tribe } \\
\hline Hausa/Fulani & $6.65(6.28-7.03)$ & $<0.001$ & $1.40(1.17-1.67)$ & $<0.001$ \\
\hline Yoruba & $1.03(0.96-1.10)$ & 0.413 & $1.27(1.06-1.51)$ & 0.008 \\
\hline \multicolumn{5}{|l|}{ Igbo } \\
\hline Others & $2.73(2.59-2.87)$ & $<0.001$ & $1.42(1.29-1.67)$ & $<0.001$ \\
\hline \multicolumn{5}{|l|}{ Religion } \\
\hline Catholics & $1.03(0.98-1.08)$ & 0.26 & $0.94(0.86-1.03)$ & 0.216 \\
\hline \multicolumn{5}{|l|}{ Other Christian } \\
\hline Islam & $2.85(2.75-2.95)$ & $<0.001$ & $0.83(0.85-1.03)$ & $<0.001$ \\
\hline Others & $2.89(2.70-3.08)$ & $<0.001$ & $0.93(0.82-1.05)$ & 0.250 \\
\hline \multicolumn{5}{|l|}{ Marriage Time (After 19) } \\
\hline Before age 20 years & $38.2(36.3-40.1)$ & $<0.001$ & $\mathrm{a}$ & \\
\hline \multicolumn{5}{|l|}{ Age at $1^{\text {st }}$ Marriage } \\
\hline$<15$ years & $71.1(66.4-76.2)$ & $<0.001$ & a & \\
\hline $15-19$ & $27.2(25.6-28.9)$ & $<0.001$ & & \\
\hline $20+$ years & & & & \\
\hline
\end{tabular}

\subsection{Discussions}

In this study, TP prevalence within the studied period in Nigeria was $49.6 \%$ on the average. The TP prevalence found in this study was in agreement with about $50 \%$ teenage pregnancies of which the majority were not desired in an early study in Nigeria [43]. While the lower TP prevalence among 1961-1964 cohort could be due to concealment of pregnancy cases, the higher prevalence reported among 1975-1979 cohort might be a product of poor knowledge and non-use of contraceptive earlier identified as a risk factor [36]. 
In contrast to most previous studies, the present study used the date of the first occurrence of pregnancy during teenage years among all women who had passed the teenage years as at the time of survey to estimate the prevalence of TP in Nigeria. We included all possible forms as well as outcomes of pregnancy before the respondents attained the age of 20 years. Hitherto, most studies have estimated TP using prevalence of pregnancy among teenagers in cross-sectional studies [19-20, 41, 44-45] and this has grossly underestimated TP in Nigeria and in some other places. Estimation of TP among current teenagers would seriously underestimate the burden of TP, undermine the findings and affect the effectiveness of intervention programmes. TP is better calculated among those who have completed teenage years [42] and should cover all forms of pregnancy endpoints among those who ever conceived, whether delivered, miscarried or aborted.

The strength of the current study was its ability to follow the pregnancy history of current adults during their teenage years in a large pooled nationally representative data conducted over a space of 23 years to arrive at TP levels. This approach overcomes the problem of under-reporting usually associated with the estimation of TP only among current teenagers. However, the secondary nature of the data limited our choices of explanatory variables. For instance, it would have been more desirable to have included the usage and knowledge of MC among the respondents when they were teenagers rather than comparisons with responses by current teenagers. Also, we relied solely on the self-reported dates of pregnancies by the respondents without any means of verification. This might have been affected by recall bias and be responsible for the observed heaping of responses at nodal ages. In addition, the data might also have been affected by the respondents' preference for socially desirable answers. We were unable to address male barriers to contraceptives, such as partner/spouse not allowing the girl to access contraceptives as such data was not part of the retrospective data studied. This might warrant further studies.

However, a review of the NDHS reports over the periods we studied shows that on the average, MC awareness and utilization among teenagers were $62.3 \%$ and $4.3 \%$ respectively $[34,41]$ but with a gradual increase between 1985 and 2013. In particular, the use of MC among teenagers rose from $2.2 \%$ in 1985-1990 to 4.5\% between 1990 and 1997, fell between 2003 and 2007 and shot up to 5.3\% between 2008 and 2013. Similarly, there was a gradual increase in the awareness of MC among teenagers over the studied period. For instance, MC awareness surged from 39.3\% in 1990 to $74.3 \%$ in 2013, although there was a decline in the trend between 2003 and 2007 at 59.3\%. It is striking that the reduction observed in the awareness of MC during the 2008 survey was accompanied by a decline in MC use during the same period. Despite Nigeria government's intensified efforts to improve MC utilization as well as local and international stakeholders' enlarged and enhanced programs on MC utilization, TP has not buckled in Nigeria. Our finding is in agreement with one of the notable findings of a systemic review conducted in the US [46] where the authors asserted that emergency contraceptive use has not changed the rate of TP in the US. The gradual increments in MC awareness and usage among teenagers in Nigeria between 1985 and 2013 did not produce a significant reduction in TP during the same period.

The TP trend in Nigeria fluctuated throughout the study period and seemed to have ended on an increasing note. This finding is further attested to by the predicted trend of TP prevalence of slightly above $50 \%$ by the year 2016 . This result is a clear cut from what is obtainable elsewhere, where a significant reduction in TP has been recorded [25]. The Nigeria situation is worrisome, bearing in mind that TP is one of the major global public health and social problems [8-9]. While adequate and effective usage of MC will reduce STDs [8], it might not impact on TP [22, 38-40]. In other climes, reduction in TP has been attributed to significant uptake of contraceptives among the sexually active female teenagers [29]. Already, the significant decrease in TP in the US over time has been tied to an increase in contraceptive use as a result of enhanced sexual education [25, 47-48]. Intervention should, therefore, focus on contraceptive use and not only on awareness.

Socio-demographic factors such as age at first marriage, education, wealth status and the zone of residence are known to influence TP [20,36]. Also, age at first marriage, which has been reported as a risk factor for adolescent pregnancy in previous studies[11, 49-50] significantly influenced TP in the current study. Girls who married before attaining age 20 years have higher odds of TP than others. The situation is worse among teenagers that got married before age 15 years. Adequate enlightenment and community efforts will be necessary to discourage the popular practice of girl-child betrothal especially in Northern Nigeria [49-51]. Delay of age at first marriage among girls opens doors of opportunities as it allows the girl to have better education, enhances future empowerment and job opportunities, delays sexual initiation, minimizes TP and reduces negative health consequences of TP $[48,50]$.

Educational attainment and wealth quintile which are direct links between characteristics of parents and children are major risk factors for TP. Teenagers from households in poorer wealth quintiles and those with no formal education, Qur'anic or primary education are more susceptible to TP. This is in consonance with literature that low education and poor empowerment could cause TP $[19-20,30,36]$. Also, earlier studies found TP to be higher in economically poorer households [8-9, 13-14, 19-20, 30] since 
economic and social disadvantages, which are offshoots of poverty and weak education, are bi-directional to TP. They are among the leading causes and consequences of TP [16, 20, 48] and they could give rise to chains of intergenerational poverty and low educational attainment if left unabated. There is a need to ensure that the girl-child is equipped with a timely and qualitative education, as well as accessible, affordable and socially acceptable contraceptives.

Geographical differences existed in the likelihood of TP. For instance, TP is much higher in the Northern zones of Nigeria than in the Southern zones just as TP is about a third more likely in South-South than in the South-West. Specifically, almost half of the respondents from the South-South zone of Nigeria were pregnant before age 20 years. Again, the higher rate of TP in these zones could be attributed to poor knowledge and non-use of contraceptives in the areas. Fagbamigbe et al had already established that poverty was much higher in Northern Nigeria than in the southern parts [52]. This could have affected the propensity of women in such regions to use MC. Also, the high rate of TP in areas where Islam is prevalent and in the Hausa/Fulani dominated northern Nigeria could be linked to lower economic status, lower level of education and early marriage which has a direct link to higher-fertility preferences.

\section{CONCLUSION}

As evidenced by our study, one of every two girls exiting the teen years is likely to have experienced at least one episode of pregnancy in Nigeria, supporting earlier findings. This finding is despite Nigeria's huge financial commitment to achieving CPR of $36 \%$ by 2018 . As far as TP is concerned in Nigeria, the impact of the massive campaign on MC use is far from being adequately felt. Although our study revealed increments in the prevalence of both MC awareness and usage, the usage was abysmally low. We opined that contraceptive use had a bi-directional influence on TP and was responsible for the no-effect status of MC usage on TP. On one hand, pregnancy rates might have decreased among those who would have had sex with or without contraceptives. On the other hand, there might have been an increase in TP among those who would have abstained from sex if not for their reliance on contraceptives. Earlier studies have shown that "unintended consequences" of contraceptive use. Access to emergency contraception not only did not reduce teenage/unwanted pregnancy rates but led to an increase in risky sexual activity and, as a result, increases in STIs. Also, Paton et al provided further evidence that cuts in spending on contraceptive services can result in lower teenage pregnancy rates. However, the consistency of our results with these more formal empirical studies is an affirmation that our findings, which were based on detection of association and not causality, that more contraception does not reduce TP holds.

While we strongly agree that adolescents should delay sexual activities until they are fully ready to bear its health, social, emotional, physical, and financial consequences, there must be an effective TP prevention strategy for those who cannot stay away from sexual intercourse. Already, about $60 \%$ of unmarried teenagers in Nigeria have reportedly had sex before age 20 years. To reduce the risks of TP and untoward health consequences of teenage sexual activities, teen pregnancy prevention initiatives must be re-strategized and strengthened. To achieve the objective of fewer teenage pregnancies, fewer resources should be spent on access to contraception and instead diverted to areas more likely to achieve results such as improvements in educational achievement amongst girls. The initiative should focus on sex education, and access to contraceptives and youth development since the adequate, correct and consistent use of effective contraceptives lowers pregnancy risks. As suggested in an earlier study, abstinence or education alone cannot prevent TP, rather a mixture of both, as well as a dire realization of the possibility of being infected with HIV and other STDs, will help curb the menace of TP. Also, the issue of early marriage must be squarely addressed at the individual, community, and national levels. We recommend that TP should be estimated using the pregnancy history of women who had already exited teen years rather than among "current" teenagers so as to correctly capture the menace.

\section{ACKNOWLEDGEMENTS}

We acknowledge ICF macro and the National Population Council on behalf of the Federal government of Nigeria granting us access to the data used for this study.

\section{REFERENCES}

[1] Chau-Kuang C, Ward C, Willians K, Abdullah A. Investigating Risk Factors Affecting Teenage Pregnancy Rates in the United States. Eur. Int. J. Sci. Technol. 2013;2:41-51.

[2] Nguyen H, Shiu C, Farber N. Prevalence and Factors Associated with Teen Pregnancy in Vietnam : Results from Two. Societies. 2016;6:1-7. 
[3] Simigiu A. Teen Pregnancy, Factors, Options, Consequences. AFASES 2012. Brasvov; 2012. p. 1-12.

[4] Kyei KA. Kyei, K.A. (2012) Teenage Fertility in Vhembe District in Limpopo Province, How High is that? $J$. Emerg. Trends Econ. Manag. Sci. 2012;3:134-40.

[5] Mersal FA, Esmat OM, Khalil GM. Effect of prenatal counselling on compliance and outcomes of teenage pregnancy. East. Mediterr. Heal. J. 2013;19:10-7.

[6] Girma S, Paton D. Is education the best contraception: The case of teenage pregnancy in England? Soc Sci Med. 2015;131:1-9.

[7] Whitworth M, Cockeril R, Lamb Lh. Antenatal management of teenage pregnancy. Obs. Gyn Repro Med. 2017;27:5056.

[8] Cook SMC, Cameron ST. Social issues of teenage pregnancy. Obs. Gyn Repro Med. 2017;27:327-32.

[9] Hadley A. Teenage pregnancy: strategies for prevention. Obs. Gyn Repro Med. 2018;28:99-104.

[10] UNFPA. Teenage pregnancy on the rise [Internet]. 2013 [cited 2015 Nov 11]. Available from: http://countryoffice.unfpa.org/botswana/2013/12/06/8624/teenage_pregnancy_on_the_rise/

[11] Tilahun M, Ayele G. Factors associated with age at first sexual initiation among youths in Gamo Gofa, South West Ethiopia : a cross sectional study. BMC Public Health [Internet]. BMC Public Health; 2013;13:1-6. Available from: BMC Public Health

[12] Guttmacher Institute. Adolescent Pregnancy and Its Outcomes Across Countries [Internet]. Adolesc. Pregnancy Its Outcomes Across Ctries. 2016 [cited 2016 Jul 30]. p. 1-5. Available from: www.guttmacher.org/factsheet/adolescent-pregnancy-and-its-outcomes-across-countries

[13] Marcen M, Bellido H. Teen Mothers and Culture [Internet]. Munich Pers. RePEc Arch. (MPRA), Pap. No. 44712. 2013 [cited 2016 Jun 14]. p. 1-39. Available from: http://mpra.ub.uni-muenchen.de/44712/MPRA

[14] Sonfield A, Hasstedt K, Javanaugh L, Anderson R. The Social and Economic Benefits of Women's Ability to Determine Whether and When to Have Children [Internet]. Guttmacher Inst. 2013 [cited 2016 Jun 16]. p. 1-13. Available from: , Guttmacher Institute

[15] Population Reference Bureau. The World's Youth 2013 Data Sheet [Internet]. Washington DC; 2013. Available from: www.prb.org

[16] Fagbamigbe AF, Idemudia ES. Does Gender and Age at Sexual Initiation affect Modern Contraceptive Use among Teenagers and Young adults in Nigeria? Gend. Behav. 2015;13:6710-9.

[17] The Centre for Social Justice. Fully committed? How a Government could reverse family breakdown [Internet]. Breakthr. Britain 2015. 2014 [cited 2016 Jul 5]. p. 1-33. Available from: http://www.centreforsocialjustice.org.uk/UserStorage/pdf/Pdf reports/CSJJ2072_Family_Breakdown.pdf

[18] Rudd A, Osborne S, Burt L, Beer G, James M. The Morning After: A Cross Party Inquiry into Unplanned Pregnancy [Internet]. London 2020 Heal. 2013 [cited 2016 Jul 15]. p. 2. Available from: http://www.2020health.org/dms/2020health/downloads/reports/2020UNPREGnew_FINAL.pdf.

[19] Ayele WM. Differentials of Early Teenage Pregnancy in Ethiopia , [Internet]. New York; 2013. Report No.: 90. Available from: https://dhsprogram.com/pubs/pdf/WP90/WP90.pdf

[20] Ajala AO. Factors associated with teenage pregnancy and fertility in Nigeria. J. Econ. Sustain. Dev. 2014;5:62-70.

[21] Miller BC. Family influences on adolescent sexual and contraceptive behaviour. J. Sex Res. 2006;39:22-6.

[22] Paton D, Wright L. The effect of spending cuts on teen pregnancy. J. Health Econ. 2017;54:135-46.

[23] Stanger-hall KF, Hall DW. Abstinence-Only Education and Teen Pregnancy Rates : Why We Need Comprehensive Sex Education in the U. S . PLoS One. 2011;6:1-11.

[24] Clifton D, Hervish A. The World's Youth 2013 Data Sheet. Washington, DC; 2013.

[25] Centers for Disease Control and Prevention (CDC). Teen Pregnancy in the United States [Internet]. About Teen Pregnancy. 2016 [cited 2016 Aug 1]. p. 1-3. Available from: http://www.cdc.gov/teenpregnancy/about/index.htm

[26] Kost K, Maddow-zimet I. U . S . Teenage Pregnancies , Births and Abortions, 2011 : State Trends by Age, Race and Ethnicity [Internet]. New York; 2016. Available from: https://www.guttmacher.org/sites/default/files/report_pdf/us-teen-pregnancy-state-trends-2011_4.pdf

[27] WHO. Adolescent pregnancy [Internet]. Matern. newborn, child Adolesc. Heal. Adolesc. pregnancy. 2016 [cited 2016 Jul 30]. 3 p. 1-26. Available from: http://www.who.int/maternal_child_adolescent/topics/maternal/adolescent_pregnancy/en/

[28] Smith DM, Mills TA. Introduction in Younger mothers and older mothers: Maternal age and maternity care. Mills, T.A., Smith D. and DTL, editor. London: Quay Books; 2012.

[29] Solomon-Fears C. Teenage Pregnancy Prevention: Statistics and Programs. Congr. Res. Serv. [Internet]. 2015;75700:1-27. Available from: https://www.fas.org/sgp/crs/misc/RS20301.pdf

[30] Alexander M, McKay A. Trends in teen pregnancy in Canada with comparisons to U.S.A. and England/Wales. Can. J. Hum. Sex. [Internet]. 2006;15:157-61. Available from: http://search.ebscohost.com/login.aspx?direct=true \&db=ccm\&AN=2009638751\&site=ehost-live 
[31] National Population Commission. Nigeria Over 167 Million [Internet]. 2013. Available from: http://www.population.gov.ng/index.php/84-news/latest/106-nigeria-over-167-million-population-implications-andchallenges

[32] World Vision. Untying the knot: Exploring Early Marriage in Fragile States. [Internet]. 2013 [cited 2016 Aug 1]. p. 1-6. Available from: www.worldvision.org.uk

[33] National Population Commission. Teenage pregnancy on the rise in Nigeria [Internet]. 2013 [cited 2016 Aug 1]. p. 1-2. Available from: http://sputniknews.com/voiceofrussia/2013_07_15/Teenage-pregnancy-on-the-rise-inNigeria-7658/

[34] National Population Commission (Nigeria) and ICF International. Nigeria Demographic and Health Survey, 2008. DHS Measure Macro, New York and Nigeria Population Commission, Abuja, Nigeria; 2009.

[35] Marteleto LJ, Dondero M. Maternal age at first birth and adolescent education in Brazil. Demogr. Res. [Internet]. 2013;28:793-820. Available from: www.demographicresearch.org/Volumes/Vol28/28/

[36] Adeyanju AB, Afolayan JA, Babafemi AA, Adeleke AJ. Health and Social Problems of Teenage Pregnancy and Future Childbearing in Amassoma Community, Bayelsa State, Nigeria. Res. J. Med. Sci. 2012;6:251-60.

[37] UK Aid. London summit on family Planning: Summaries of Commitments. 2013;10. Available from: http://www.familyplanning2020.org/images/content/documents/London_Summit_Commitments_12-2-2013.pdf

[38] Sourafel Girma, Paton D. Matching estimates of the impact of over-the-counter emergency birth control on teenage pregnancy. Health Econ. 2006;15:1021-32.

[39] Mulligan K. Access to Emergency Contraception and its Impact on Fertility and Sexual Behavior. Health Econ. 2016;25:1-6.

[40] Girma S, Paton D. The impact of emergency birth control on teen pregnancy and STIs. J. Health Econ. 2010;30:373-80.

[41] National Population Commission (Nigeria) and ICF International. Nigeria Demographic and Health Survey 2013. Abuja, Nigeria; 2014.

[42] Loaiza E, Liang M. Adolescent pregnancy : A review of the evidence. UNFPA. New York; 2013.

[43] Gilda S, Akinrinola B, Boniface OA, Adewole IF, Singh S, Hussain R. Unwanted pregnancy and associated factors among Nigerian women. Int. Fam. Plan. Perspect. 2006;32:175-84.

[44] Pendse R, Mcclure K, Mouli V, Health A, Mathai M, Portela a. Adolescent Pregnancy. WHO MPS Notes. 2008;1:1-4.

[45] Federal Ministry of Health Nigeria. National HIV/AIDS and Reproductive Health and Serological Survey, 2012 (NARHS Plus),. Federal Ministry of Health, Abuja, Nigeria; 2013.

[46] Raymond EG et al. Population effect of increased access to emergency contraception pills: a systematic review. Obstet. Gynecol. 2007;109:181-8.

[47] Hofferth SL, Cheryl DH. Risking the Future: Adolescent Sexuality, Pregnancy, and Childbearing, Volume II: Working Papers and Statistical Appendices. II. Council P on AP and CC on B and SS and ED of B and SS and ENR, editor. Washington DC: National Academies Press (US); 1987.

[48] Advocates for Youth. Analysis of Recent Trends \& Federal Expenditures Associated with Teenage Pregnancy [Internet]. Teenage Pregnancy, Case Prev. 2016 [cited 2016 Sep 14]. p. 1-5. Available from: http://www.advocatesforyouth.org/publications/publications-a-z/387-teenage-pregnancy-the-case-for-prevention

[49] Adebowale AS, Fagbamigbe AF, Okareh TO, Lawal GO. Survival Analysis of Timing of First Marriage among Women of Reproductive age in Nigeria : Regional Differences. Afr. J. Reprod. Health. 2012;16:95-107.

[50] Fagbamigbe AF, Idemudia ES. Survival analysis and prognostic factors of timing of first childbirth among women in Nigeria. BMC Pregnancy Childbirth [Internet]. BMC Pregnancy and Childbirth; 2016;16:1-12. Available from: http://dx.doi.org/10.1186/s12884-016-0895-y

[51] Doctor H, Findley S, Afenyadu G, Uzondu C, Ashir G. Awareness, use, and unmet need for family planning in rural northern Nigeria. Afr J Rep Heal. 2013;17:107-17.

[52] Fagbamigbe AF, Bamgboye EA, Yusuf BO, Akinyemi JO, Issa BK, Ngige E, et al. The Nigeria wealth distribution and health seeking behaviour : evidence from the 2012 national HIV / AIDS and reproductive health survey. Health Econ. Rev. 2015;5:e1-10. 